\title{
Oridonin inhibits growth and induces apoptosis of human neurocytoma cells via the Wnt/ $\beta$-catenin pathway
}

\author{
JINGYAN LIANG ${ }^{1-4}$, WEIGUANG WANG ${ }^{5}$, LIFU WEI $^{6}$, SHAN GAO $^{7}$ and YINGGE WANG ${ }^{2-4,6,8}$ \\ ${ }^{1}$ Department of Anatomy, College of Medicine; ${ }^{2}$ The Research Center for Vascular Biology, College of Medicine; ${ }^{3}$ Jiangsu \\ Key Laboratory of Integrated Traditional Chinese and Western Medicine for Prevention and Treatment of Senile Disease; \\ ${ }^{4}$ Jiangsu Co-Innovation Center for Prevention and Control of Important Animal Infectious Disease and Zoonoses, \\ Yangzhou University, Yangzhou, Jiangsu 225009; ${ }^{5}$ Department of Hematology, First Affiliated Hospital of Jiamusi \\ University, Jiamusi, Heilongjiang 154003; ${ }^{6}$ Department of Neurology, Affiliated Hospital of Yangzhou University, \\ Yangzhou, Jiangsu 225001; ${ }^{7}$ Department of Neurology, Shanghai JiaoTong University Affiliated Sixth People Hospital, \\ South Campus, Shanghai 200233; ${ }^{8}$ Mobile Post-doctoral Research Station of \\ Yangzhou University, Yangzhou 225009, P.R. China
}

Received December 11, 2015; Accepted April 20, 2018

DOI: $10.3892 / \mathrm{ol} .2018 .8977$

\begin{abstract}
Central neurocytoma $(\mathrm{CN})$ is a rare periventricular tumor of the central nervous system in young adults. Typically, patients with $\mathrm{CN}$ exhibit a favorable prognosis, but in certain cases the clinical course is more aggressive. Therefore, investigating effective therapeutic approaches is important. Oridonin has attracted attention due to its antitumor activities. However, the role of oridonin in tumorigenesis and progression remains unknown. The present study examined the antitumor function of oridonin in $\mathrm{CN}$ cells, and investigated the underlying molecular mechanism. An MTT assay suggested that treatment with oridonin was able to significantly inhibit the proliferation of CN cells. The annexin V-fluorescein isothiocyanate/propidium iodide assay and western blot analysis demonstrated that oridonin was able to induce apoptosis and alter the expression of apoptosis-associated proteins by downregulating anti-apoptotic protein, B-cell lymphoma-2 (Bcl-2), and upregulating pro-apoptosis proteins, Bcl-2-like protein 4, cleaved caspase-3 and cleaved poly(ADP-ribose) polymerase 1 . Subsequently, the $\mathrm{Wnt} / \beta$-catenin signaling pathway was examined. Western blot analysis indicated that oridonin markedly decreased the expression of $\beta$-catenin, cyclin D1 and v-myc avian myelocytomatosis viral oncogene homolog. Furthermore, $\beta$-catenin was silenced by small interference RNA or overexpressed in
\end{abstract}

Correspondence to: Dr Yingge Wang, The Research Center for Vascular Biology, College of Medicine, Yangzhou University, 88 South University Avenue, Hanjiang, Yangzhou, Jiangsu 225009, P.R. China

E-mail: yinggeww88@sina.com

Key words: oridonin, proliferation, apoptosis, central neurocytoma, Wnt/ $\beta$-catenin signaling
$\mathrm{CN}$ cells, and the effect on cell proliferation was examined. The results indicated that silencing of $\beta$-catenin enhanced the inhibitory effect of oridonin on cell growth, whereas the overexpression of $\beta$-catenin attenuated this effect. These data indicated that oridonin inhibited proliferation and induced apoptosis to exert its antitumor activity in $\mathrm{CN}$ cells by repressing Wnt/ $\beta$-catenin signaling. Therefore, the present study suggested that oridonin might be an effective adjuvant agent, and that the Wnt/ $\beta$-catenin signaling pathway may be a potent target for the therapy in $\mathrm{CN}$.

\section{Introduction}

Central neurocytoma $(\mathrm{CN})$ is a rare but usually benign neuronal tumor composed of uniform round cells with neuronal differentiation and typically located in the supratentorial ventricles in young adults $(1,2)$. Surgery and radiotherapy are widely considered as the most important therapeutic approaches for CN. Patients with CN commonly exhibit a good prognosis, but in certain cases the clinical course is more aggressive or is followed by recurrence (3). Chemotherapy may be useful for recurrent $\mathrm{CN}$ that cannot be resected and has been radiated. Therefore, it is necessary to develop effective antitumor drugs for adjuvant therapy of $\mathrm{CN}$. In particular, the combination of antitumor drugs with molecular target therapy may greatly improve the prognosis of $\mathrm{CN}$.

Oridonin, a diterpenoid isolated from the Chinese medicinal herb Rabdosia rubescens, exhibits potential anti-inflammatory, anti-tumor, pro-apoptotic and neurological effects $(4,5)$. Oridonin has been demonstrated to inhibit proliferation and induce apoptosis in a variety of human cancer cells, including colon, pancreatic, breast, lung and liver cancer (6-10). However, the underlying mechanisms remain poorly understood. Previously, oridonin has been demonstrated to exert antitumor activities through several signaling pathways that are associated with cell proliferation and apoptosis, including c-Jun N-terminal kinase (JNK), p38 mitogen-activated 
protein kinase (MAPK), extracellular signal-regulated kinase (ERK) and protein kinase B (Akt) signaling pathways $(11,12)$. Although oridonin exhibits a significant antitumor function in multiple types of cancer, its exact effect on $\mathrm{CN}$ and the underlying mechanism remain unclear.

The Wnt/ $\beta$-catenin signaling pathway is a canonical Wnt pathway, which serves a critical role in regulating cell growth, apoptosis, motility, polarity and differentiation (13). Dysregulation of the pathway is identified in several types of cancer, including liver, colon and several types of brain tumors (14). The underlying molecular mechanisms of $\mathrm{CN}$ have been largely examined, but it has been suggested that the receptors and effectors of the Wnt pathway are differentially overexpressed in $\mathrm{CN}$ cells (15). Additionally, it has also been demonstrated that oridonin inhibits the proliferation of human osteosarcoma cells by suppressing Wnt signaling (16). Therefore, the present study hypothesized whether oridonin may inhibit the growth of $\mathrm{CN}$ cells by affecting $\mathrm{Wnt} / \beta$-catenin signaling transduction.

In the present study, the roles of oridonin in the proliferation and apoptosis of $\mathrm{CN}$ cells as well as the potential molecular mechanisms were investigated. It was indicated that oridonin was able to inhibit proliferation and induce apoptosis, which might be mediated by repressing the $\mathrm{Wnt} / \beta$-catenin signaling pathway in $\mathrm{CN}$ cells.

\section{Materials and methods}

Cell culture and treatment. Central neurocytoma tissue was obtained from 1 patient diagnosed with $\mathrm{CN}$ for cell culture following resection at the First Affiliated Hospital of Jiamusi University (Jiamusi, China). Resected tissues were stored in $\mathrm{Mg}^{2+} / \mathrm{Ca}^{2+}$-free Hank's Balanced Salt Solution (HBSS), and then cut into small pieces in piperazine-N,N'-bis(2-ethanesulfonic acid) (PIPES) solution (20 mM PIPES, $25 \mathrm{mM}$ glucose, $5 \mathrm{mM} \mathrm{KCl}, 120 \mathrm{mM} \mathrm{NaCl}$ ) and treated as previously described (17-19). The tissue samples were resuspended in Dulbecco's modified Eagle's medium/F-12/N2 medium (Gibco; Thermo Fisher Scientific, Inc., Waltham, MA, USA) supplemented with 5\% fetal bovine serum (FBS; Lonza Group, Ltd., Basel, Switzerland), $100 \mathrm{U} / \mathrm{ml}$ penicillin, $100 \mu \mathrm{g} / \mathrm{ml}$ streptomycin, $10 \mathrm{ng} / \mathrm{ml}$ epidermal growth factor (EGF) and $20 \mathrm{ng} / \mathrm{ml}$ basic fibroblast growth factor (bFGF). A total of $1 \times 10^{6}$ dissociated cells/well were plated into collagen IV (BD Biosciences, Franklin Lakes, NJ, USA) or fibronectin (Sigma-Aldrich; Merck KGaA, Darmstadt, Germany) precoated 6-well culture plate. The cells were cultured in a $37^{\circ} \mathrm{C}$ incubator with $5 \%$ $\mathrm{CO}_{2}$. The present study design was approved by the Ethics Committee of First Affiliated Hospital of Jiamusi University, and all patients provided written informed consent.

RNA interference and overexpression of $\beta$-catenin. Small interfering RNA (siRNA) targeting $\beta$-catenin (si $\beta$-catenin) and recombinant adenoviruses expressing $\beta$-catenin (Ad- $\beta$-ctn) were obtained as previously described using the AdEasy technology (20-22). The sequence of $\beta$-catenin siRNA was 5'-CAG GGGGUUGUGGUUAAGCUCUU-3'. A scramble siRNA sequence (5'-TTCTCCGAACGTGTCACGT-3') was used as a control (Gima Biol Engineering Inc., Shanghai, China). A total of $2 \times 10^{4}$ cultured central neurocytoma cells were seeded into each well of a 12-well plate and were cultured to $80 \%$ confluence. Cell transfections were performed using $100 \mathrm{nmol}$ siRNA and $5 \mu$ l Lipofectamine ${ }^{\circledR} 2000$ (Invitrogen; Thermo Fisher Scientific, Inc.), according to the manufacturer's protocol. Cells were further cultured for $48 \mathrm{~h}$ following transfection, and cells were subsequently lysed and analyzed for the protein expression of $\beta$-catenin by western blotting. In addition, cells were treated with oridonin, and then cell proliferation was detected.

Proliferation assay. Cell proliferation was assessed by MTT assay. Briefly, following transfection, $10^{4}$ cells were seeded in a 96-well flat bottom plate. The cells were cultured in a $5 \% \mathrm{CO}_{2}$ incubator at $37^{\circ} \mathrm{C}$. Once cell confluence reached $80 \%$, the supernatant was replaced with fresh medium and the cells were treated with $0,5,10,15,20$ or $25 \mu \mathrm{M}$ oridonin (Xi'an Hao-Xuan Bio-tech Co., Ltd., Xi'an, China) dissolved in dimethyl sulfoxide (DMSO) for 24, 48 or $72 \mathrm{~h}$ followed by an additional $4 \mathrm{~h}$ subsequent to the addition of $20 \mu \mathrm{l} \mathrm{MTT}$ ( $5 \mathrm{mg} / \mathrm{ml}$ ) into each well. A total of $200 \mu \mathrm{l}$ DMSO was added to the wells for cell lysis. Absorbance was detected using an ELISA spectrophotometer at $490 \mathrm{~nm}$.

Apoptosis assay. A total of $1 \times 10^{6}$ central neurocytoma cells were seeded on $60 \mathrm{~mm}$ dishes and cultured in Dulbecco's modified Eagle's/Nutrient Mixture F12 (Gibco; Thermo Fisher Scientific, Inc.) supplemented with $5 \%$ fetal bovine serum (Lonza Group, Ltd., Basel, Switzerland), $100 \mathrm{U} / \mathrm{ml}$ penicillin and $100 \mu \mathrm{g} / \mathrm{ml}$ streptomycin. When cells reached $80 \%$ confluence, they were treated with $0,10,15$ or $20 \mu \mathrm{M}$ oridonin for the indicated time. Apoptosis was quantified by Annexin V-fluorescein isothiocyanate (FITC)/propidium iodide (PI) assay (BD Biosciences, Franklin Lakes, NJ, USA) following the manufacturer's protocol. Briefly, cells were collected by trypsinization and pooled with cell supernatants from corresponding culture dishes; $500 \mu \mathrm{l}$ of this cell suspension was incubated with $2 \mu \mathrm{l}$ of Annexin-V-FITC stock solution for $15 \mathrm{~min}$ in the dark. After a short centrifugation $(300 \mathrm{x} \mathrm{g}$, $5 \mathrm{~min}$ ), cells were washed in PBS before being resuspended in $0.5 \mathrm{ml}$ of $1 \mathrm{x}$ binding buffer supplemented with $1 \mu \mathrm{PI}$ (1 $\mu \mathrm{g} / \mathrm{ml}$ final concentration). The Annexin V-FITC/PI assay detects the amount of phosphatidylserine on the outer surface of the plasma membrane (a biochemical alteration unique to membranes of apoptotic cells) and the amount of PI, a dye that easily enters dead cells or cells in the late stages of apoptosis and binds DNA but does not bind with the plasma membrane of viable cells. Fluorescence was detected using a FACSCalibur flow cytometer by fluorescence activated cell sorter (FACS) analysis, and data were analyzed using CellQuestPro version 5.2 software (BD Biosciences, San Jose, CA, USA). The cells with phosphatidylserine on their surface were considered to be apoptotic.

Western blot analysis. The cells were washed twice with PBS and were lysed with lysis buffer (50 mM Tris- $\mathrm{HCl}(\mathrm{pH} 7.4), 1$ mM EDTA, 1\% NP40, $150 \mathrm{mM} \mathrm{NaCl}, 10 \mathrm{mM} \mathrm{NaF}$ and $1 \mathrm{mM}$ $\mathrm{Na}_{3} \mathrm{VO}_{4}$ ) containing a protease inhibitor cocktail (Roche Molecular Diagnostics, Branchburg, NJ, USA). Following centrifugation at $12,000 \mathrm{x}$ for $10 \mathrm{~min}$ at $4^{\circ} \mathrm{C}$, the supernatant was collected and quantified using a bicinchoninic acid quantification kit (Beyotime Institute of Biotechnology, 
A

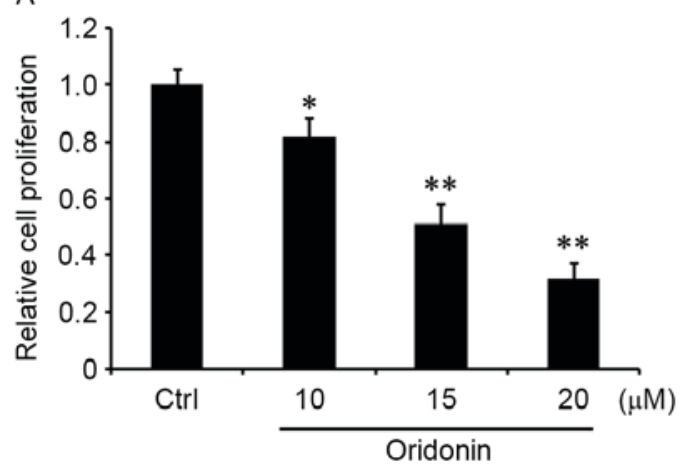

B

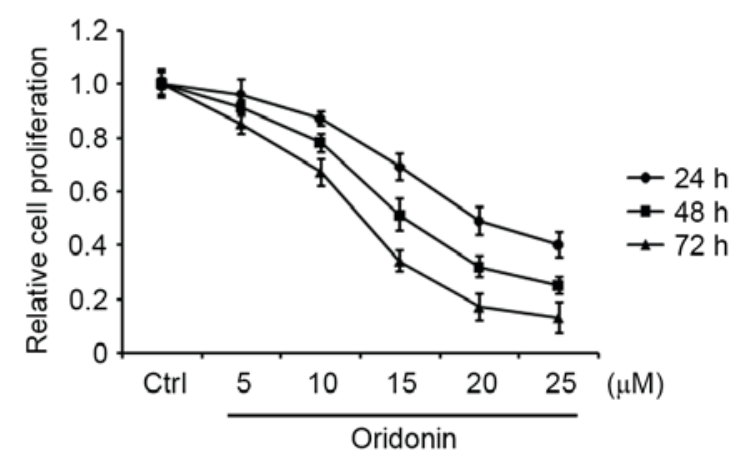

Figure 1. Effect of oridonin on the proliferation of central neurocytoma cells. The cells were seeded in 96 -well plates. Following 24 h incubation, the cells (A) were treated with 10,15 and $20 \mu \mathrm{M}$ oridonin or DMSO for $48 \mathrm{~h}$ or (B) 5, 10, 15, 20 and $25 \mu \mathrm{M}$ oridonin or DMSO for 24,48 and $72 \mathrm{~h}$. Cell proliferation was evaluated by MTT assay and compared with DMSO-treated control cells. The assays were performed in triplicate. ${ }^{*} \mathrm{P}<0.05$ and ${ }^{* *} \mathrm{P}<0.01$ vs. control. Data are presented as the mean \pm standard error of the mean. DMSO, dimethyl sulfoxide; Ctrl, control cells.

Haimen, China). $50 \mu \mathrm{g}$ proteins were loaded per lane onto $10 \%$ SDS-PAGE gels (Bio-Rad Laboratories, Inc., Hercules, CA, USA) and transferred to Immobilon-P membranes (EMD Millipore, Billerica, MA, USA). The membranes were blocked with $5 \%$ skimmed milk in Tris-buffered saline containing $0.05 \%$ Tween 20 for $1 \mathrm{~h}$ at room temperature, and incubated with the following specific primary antibodies overnight at $4^{\circ} \mathrm{C}$. The antibodies against B-cell lymphoma-2 (Bcl-2; 1:500; catalogue no. sc7382; Santa Cruz Biotechnology, Inc., Dallas, TX, USA), Bcl-2-like protein 4 (Bax; 1:500; cat no. sc493; Santa Cruz Biotechnology, Inc.), cleaved caspase-3 (1:1,000; cat no. 9661S; Cell Signaling Technology, Inc., Danvers, MA, USA) and cleaved poly (ADP-ribose) polymerase 1 (cleaved PARP; 1:1,000; catalogue no. 9541; Cell Signaling Technology, Inc.), $\beta$-catenin (1:500; catalogue no. sc1496; Santa Cruz Biotechnology, Inc.), cyclin D1 (1:1,000; catalogue no. sc20044; Santa Cruz Biotechnology, Inc.), v-myc avian myelocytomatosis viral oncogene homolog (c-Myc; 1:1,000; catalogue no. sc788; Santa Cruz Biotechnology,Inc.) and $\beta$-actin (1:1,000; catalogue no. sc47778; Santa Cruz Biotechnology, Inc.) were used for detection. This was followed by incubation with horseradish peroxidase-conjugated goat anti-mouse secondary antibody (1:2,000; catalogue no. sc-2005; Santa Cruz Biotechnology, Inc.) and anti-rabbit immunoglobulin G antibody (1:2,000; catalogue no. sc-2004; Santa Cruz Biotechnology, Inc.) for $2 \mathrm{~h}$ at room temperature. The blots were visualized using enhanced chemiluminescence detection reagent (GE Healthcare Life Sciences, Little Chalfont, UK). The gray value of the targeted bands was quantified with QuantityOne software version 4.6.2 (Bio-Rad Laboratories, Inc., Hercules, CA, USA) following incubation, with $\beta$-actin used as the internal reference.

Quantitative reverse-transcriptase polymerase chain reaction $(R T-q P C R)$. Total RNA was extracted from cells using TRIzol reagent according to the manufacturer's protocol (Invitrogen; Thermo Fisher Scientific, Inc., Waltham, MA, USA). cDNA was generated with reverse transcription using the RevertAid ${ }^{\mathrm{TM}}$ First Strand cDNA synthesis kit (Fermentas, Thermo Fisher Scientific, Inc., Pittsburgh, PA, USA) and was amplified using a TaqMan ${ }^{\circledR}$ Gene Expression Assay (Applied biosystems; Thermo Fisher Scientific, Inc.) with fluorogenic carboxyfluorescein-labeled probes using specific primers for target proteins. The specific primers for PCR were forward, 5'-ACCAGTGGATTCTGTGTTGTT-3' and reverse, 5'-ATT TGAAGGCAGTCTGTCGTA-3' for $\beta$-catenin and forward, 5'-GATCCCTCCAAAATCAAGTG-3' and reverse, 5'-GAG TCCTTCCACGATACCAA-3' for GAPDH. Real-time fluorescence detection was performed with the ABI PRISM 7700 Sequence Detector (Applied Biosystems; Thermo Fisher Scientific, Inc.). PCR involved 40 amplification cycles of $94^{\circ} \mathrm{C}$ for $10 \mathrm{sec}, 53^{\circ} \mathrm{C}$ for $30 \mathrm{sec}$ and $72^{\circ} \mathrm{C}$ for $40 \mathrm{sec}$, followed by final extension at $72^{\circ} \mathrm{C}$ for $10 \mathrm{~min}$. $\beta$-catenin expression was normalized to GAPDH expression and calculated using the $2^{-\Delta \Delta \mathrm{Ct}}$ formula (23). The relative level of $\beta$-catenin mRNA was presented as a percentage of the control.

Statistical analysis. All of the experiments were repeated at least 3 times. SPSS (version 16.0; SPSS, Inc., Chicago, IL, USA) was used to analyze the experimental data. One-way analysis of variance was used to assess the differences between the groups. Duncan's multiple range test was employed for pairwise comparison and followed by Bonferroni correction. The data are presented as the mean \pm standard error of the mean. $\mathrm{P}<0.05$ (two-tailed) was considered statistically significant difference.

\section{Results}

Oridonin suppresses the proliferation of $C N$ cells. To determine the role of oridonin in $\mathrm{CN}$ cells, $\mathrm{CN}$ tissue was obtained from one patient diagnosed with $\mathrm{CN}$ following resection, and a CN cell line was generated by primary culture (17-19). The cells were grown in the medium for $24 \mathrm{~h}$, and then treated with 10,15 and $20 \mu \mathrm{M}$ oridonin for $48 \mathrm{~h}$ or were treated with $5,10,15,20$ or $25 \mu \mathrm{M}$ oridonin for 24,48 or $72 \mathrm{~h}$. An MTT assay was performed to evaluate cell proliferation. The results demonstrated that oridonin was able to markedly decrease the proliferation of $\mathrm{CN}$ cells in a concentration- and time-dependent manner relative to the DMSO-treated control (Fig. 1A and B).

Oridonin induces the apoptosis of CN cells. To confirm whether the inhibition of proliferation that is mediated by oridonin is associated with cell apoptosis, the cells were treated with 10 , 

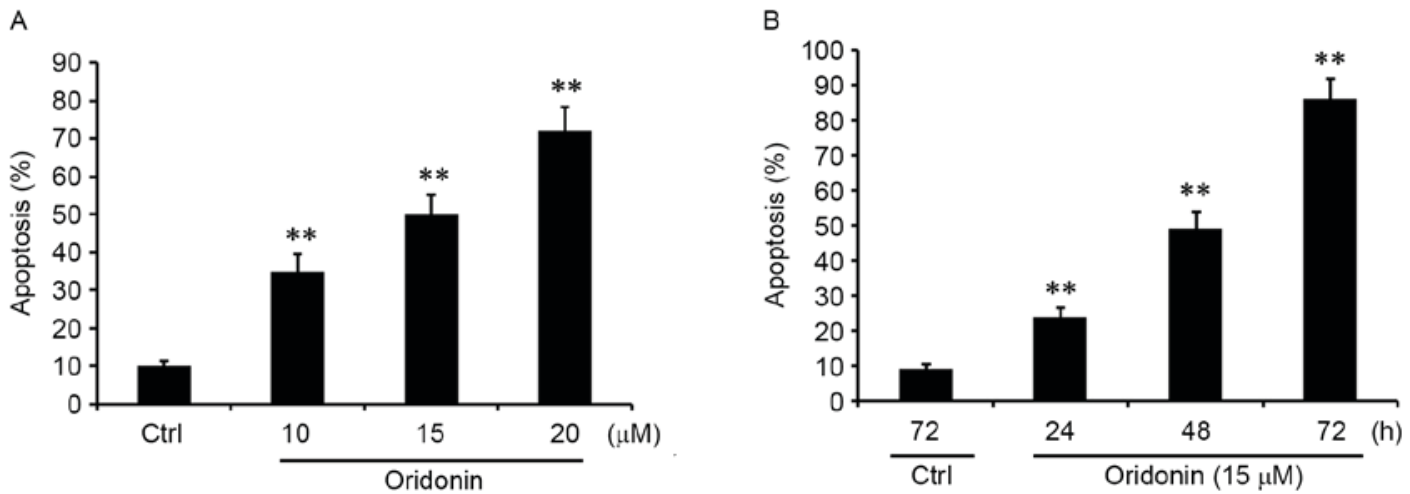

Figure 2. Oridonin induces the apoptosis of central neurocytoma cells in a concentration- and time-dependent manner. (A) CN cells were treated with 10,15 and $20 \mu \mathrm{M}$ oridonin or DMSO for $48 \mathrm{~h}$. The effect of oridonin on apoptosis was determined by FACS assay. (B) The cells were treated with $15 \mu \mathrm{M}$ oridonin for 24, 48 and $72 \mathrm{~h}$, and DMSO-treated control cells were cultured for $72 \mathrm{~h}$. The proapoptotic property of oridonin was assessed by FACS assay. The assays were performed in triplicate. ${ }^{* *} \mathrm{P}<0.01$ vs. control, mean \pm standard error of the mean. Ctrl, DMSO-treated control cells; FACS, fluorescence activated cell sorter.

A

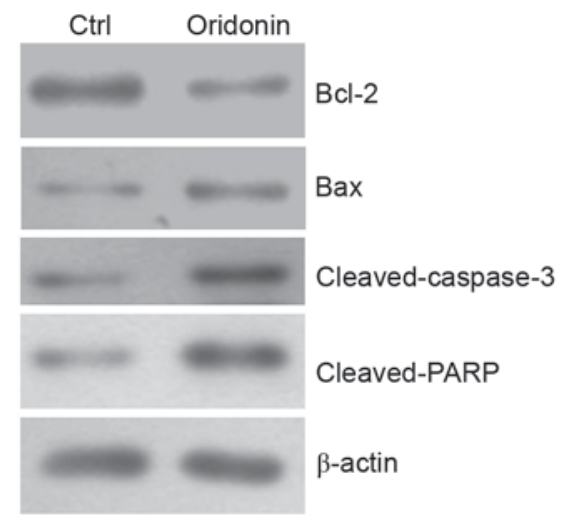

C

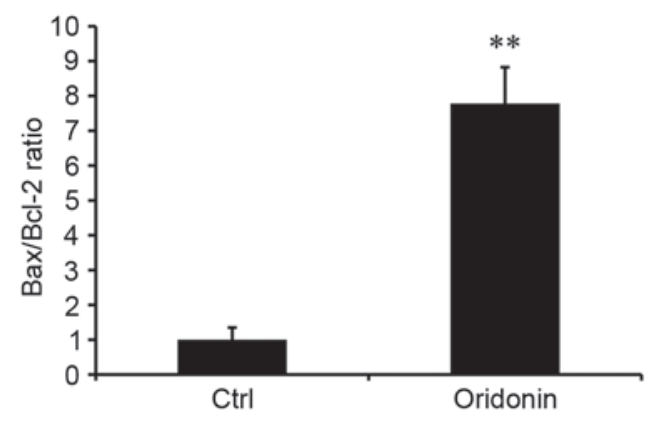

B

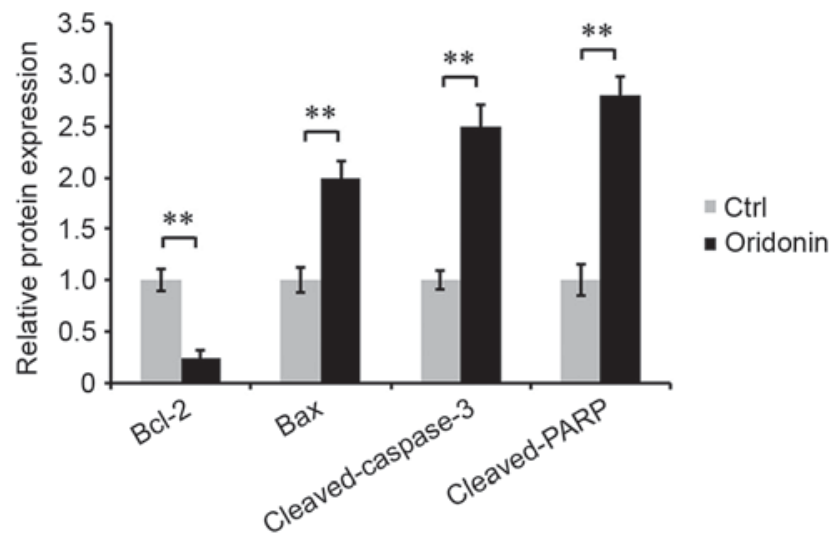

Figure 3. Oridonin alters the expression of apoptosis-associated proteins in central neurocytoma cells. (A) The levels of Bcl-2, Bax, cleaved caspase-3 and cleaved PARP proteins in oridonin-treated cells and DMSO-treated control cells were detected by western blotting using respective specific antibodies. $\beta$-actin was used as the loading control. (B) Protein levels were quantified. ${ }^{* *} \mathrm{P}<0.01$. (C) The Bax/Bcl-2 ratio was calculated by dividing the value for Bax expression by the value for Bcl-2 expression. The assay was performed in triplicate. ${ }^{* *} \mathrm{P}<0.01$ vs. ctrl. Mean \pm standard error of the mean. DMSO, dimethyl sulfoxide; Bcl-2, B-cell lymphoma 2; Bax, BCL-2-like protein 4; PARP, poly(ADP-ribose) polymerase 1; Ctrl, DMSO-treated control cells.

15 and $20 \mu \mathrm{M}$ oridonin for $48 \mathrm{~h}$. Apoptosis was quantified by FACS analyses. The results demonstrated that oridonin treatment was able to significantly promote the apoptosis of CN cells in a concentration-dependent manner (Fig. 2A). Additionally, $\mathrm{CN}$ cells were treated with $15 \mu \mathrm{M}$ oridonin for 24, 48 and $72 \mathrm{~h}$. It was identified that apoptosis was induced by oridonin in a time-dependent manner (Fig. 2B). These results were consistent with the pattern observed with the inhibition of proliferation, suggesting that oridonin acted as a potent apoptotic inducer in $\mathrm{CN}$ cells.
Oridonin affects the expression of apoptosis-associated proteins in $\mathrm{CN}$ cells. To additionally determine the role of oridonin in the apoptosis of CN cells, western blotting was performed to assess the expression levels of apoptosis-associated proteins: Bcl-2, Bax, cleaved caspase-3 and cleaved PARP. The results demonstrated that the expression of Bcl-2, an anti-apoptotic protein, was significantly reduced in oridonin-treated CN cells compared with control cells. By contrast, the expression levels of pro-apoptosis protein Bax, cleaved caspase-3 and cleaved PARP were increased (Fig. 3A 
A

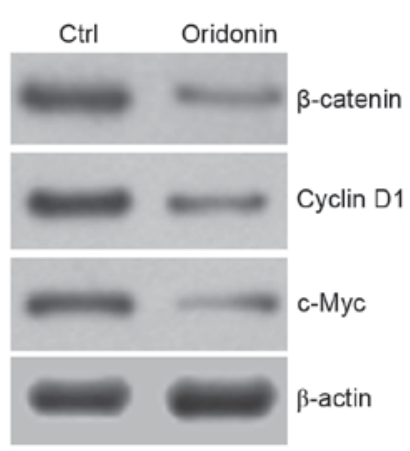

B

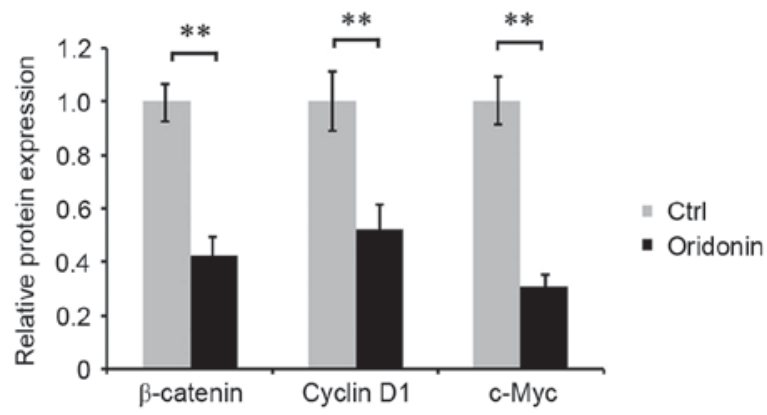

Figure 4. Oridonin downregulates the Wnt/ $\beta$-catenin signaling pathway. (A) The levels of $\beta$-catenin, cyclin D1 and c-Myc proteins in central neurocytoma cells that were treated with or without oridonin as evaluated by western blotting using respective specific antibodies. $\beta$-actin was detected as the internal reference. (B) Target protein expression normalized to $\beta$-actin expression is indicated by the bar graph. The assay was performed in triplicate. ${ }^{* *} \mathrm{P}<0.01$. Data are presented as the mean \pm standard error of the mean. c-Myc, v-myc avian myelocytomatosis viral oncogene homolog; Ctrl, dimethyl sulfoxide-treated control cells.

and $\mathrm{B}$ ), and the Bax/Bcl-2 ratio was increased (Fig. 3C). The $\mathrm{Bax} / \mathrm{Bcl}-2$ ratio is a key factor in determining the occurrence and level of apoptosis (24). These results indicated that treatment with oridonin was able to alter cell apoptosis, potentially by modulating Bcl-2, Bax, and cleaved caspase- 3 and cleaved PARP.

Oridonin downregulates the Wnt/ $\beta$-catenin signaling pathway. To investigate the molecular mechanism underlying the effect of oridonin on the growth and apoptosis of $\mathrm{CN}$ cells, the Wnt/ $\beta$-catenin signaling pathway was evaluated by detecting the expression of key proteins of this pathway. $\mathrm{CN}$ cells were treated with $15 \mu \mathrm{M}$ oridonin for $48 \mathrm{~h}$. Western blot analysis was performed, and the results indicated that treatment with oridonin was able to downregulate the accumulation of $\beta$-catenin, cyclin D1 and c-Myc in CN cells. Densitometric analysis of the western blot bands confirmed these results (Fig. 4A and B), suggesting that oridonin regulated the growth and apoptosis of $\mathrm{CN}$ cells, which is likely to be mediated by Wnt signaling.

Silencing and overexpressing $\beta$-catenin in CN cells. To verify the involvement of $\mathrm{Wnt} / \beta$-catenin signaling pathway in oridonin-mediated inhibition on proliferation of $\mathrm{CN}$ cells, $\beta$-catenin was knocked down using siRNA or was overexpressed by infecting cells with recombinant adenoviruses that expressed $\beta$-catenin in CN cells. The RNA expression level of $\beta$-catenin was examined by RT-qPCR, and protein expression was detected by western blot analysis. The results indicated that the relative $\beta$-catenin mRNA expression was markedly decreased in cells that were treated with $\beta$-catenin siRNA and the residual protein expression of $\beta$-catenin in the cells was markedly reduced compared with the control siRNA-treated cells (Fig. 5A and B). Additionally, western blot analysis indicated that $\beta$-catenin was significantly elevated in cells that overexpressed $\beta$-catenin (Fig. 5C).

Role of $\beta$-catenin in oridonin-mediated inhibition of cell proliferation. The effect of $\beta$-catenin, a key member of the Wnt signaling pathway, on oridonin-mediated inhibition of cell proliferation in $\mathrm{CN}$ cells was examined in the aforementioned cell lines. $\beta$-catenin-silenced and non-silenced $\mathrm{CN}$
A
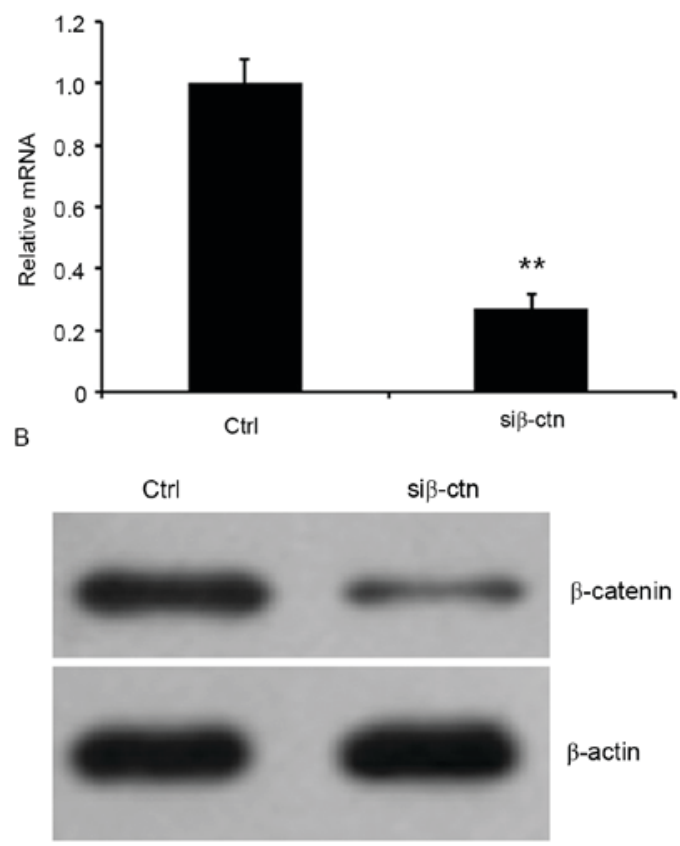

C

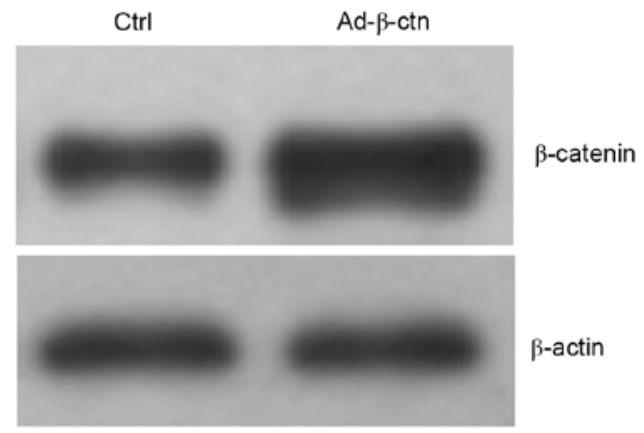

Figure 5. Silencing and overexpressing $\beta$-catenin in $\mathrm{CN}$ cells. $\beta$-catenin expression was downregulated by si- $\beta$-catenin-infected cells (si- $\beta$-ctn), and was upregulated in Ad- $\beta$-catenin-infected CN (central neurocytoma) cells (Ad- $\beta$-ctn). (A) Reverse transcription-quantitative polymerase chain reaction and (B) western blotting were performed to detect mRNA and protein expression of $\beta$-catenin in $\beta$-catenin-silenced cells (si- $\beta$-ctn) and control cells (ctrl). (C) The expression of $\beta$-catenin protein in $\beta$-catenin-overexpressed cells and ctrl cells were assessed by western blot analysis. ${ }^{* *} \mathrm{P}<0.01$ vs. control. The data are presented as the mean \pm standard error of the mean. 
A
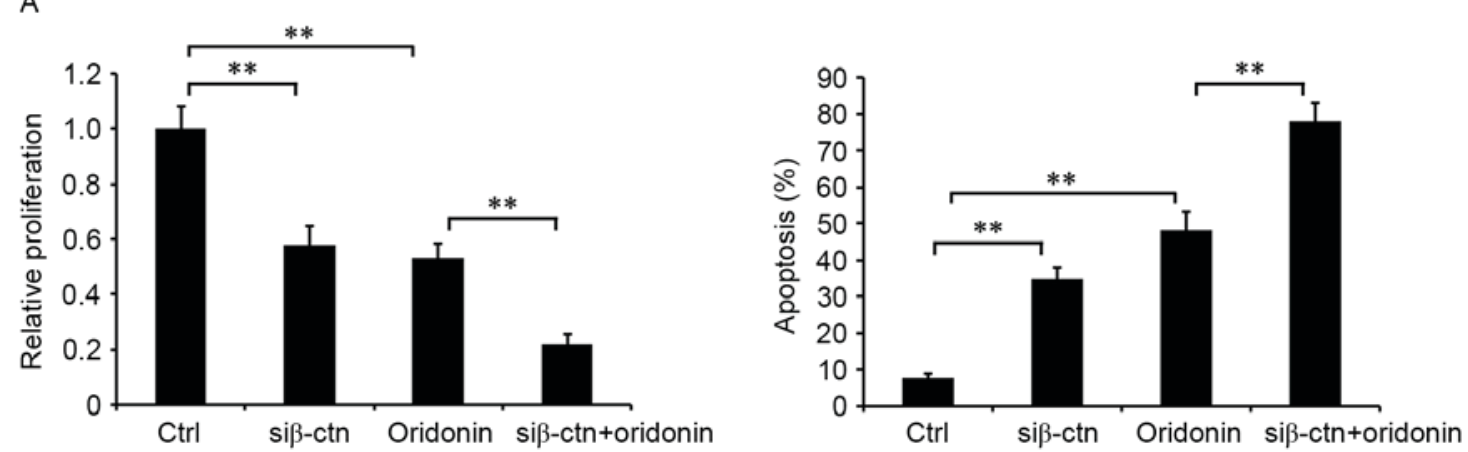

B
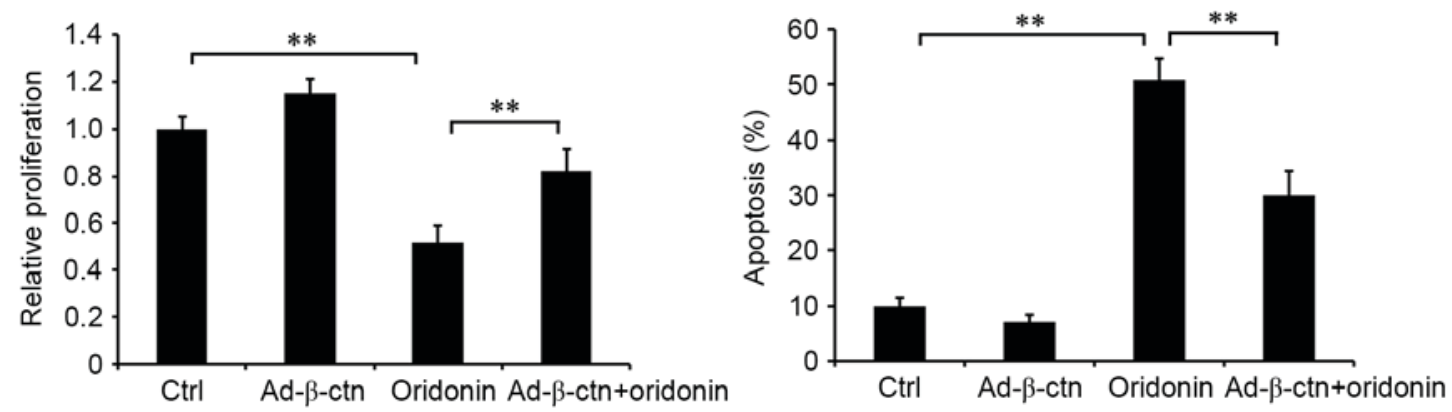

Figure 6. Role of $\beta$-catenin in oridonin-mediated inhibition on the proliferation of $\mathrm{CN}$ cells. The cells that were infected with (A) si $\beta$-catenin adenovirus or (B) Ad- $\beta$-catenin were seeded in 96-well plates and were incubated with or without $15 \mu \mathrm{M}$ oridonin. At $48 \mathrm{~h}$ following treatment, cell proliferation and apoptosis were detected and quantified. The assays were performed in triplicate. ${ }^{* *} \mathrm{P}<0.01$. The data are presented as the mean \pm standard error of the mean $\mathrm{CN}$, central neurocytoma; si $\beta$-ctn, recombinant adenovirus expressing $\beta$-catenin-siRNA; Ad- $\beta$-ctn, $\beta$-catenin-expressing adenovirus; Ctrl, ctrl, control cells.

cells were treated with or without $15 \mu \mathrm{M}$ oridonin for $48 \mathrm{~h}$. Detection of cell proliferation indicated that treatment with oridonin and silencing of $\beta$-catenin inhibited cell proliferation and induced apoptosis (Fig. 6A). The combination of oridonin treatment and silencing of $\beta$-catenin markedly augmented the effects on cell proliferation and apoptosis compared with oridonin single treatment (Fig. 6A). Additionally, the overexpression of $\beta$-catenin attenuated the effects of oridonin on proliferation and apoptosis (Fig. 6B). These data suggested that the Wnt/ $\beta$-catenin signaling pathway served an important role in the antitumor activities of oridonin in $\mathrm{CN}$ cells, and that oridonin regulated the growth of $\mathrm{CN}$ cells, which might be via the Wnt/ $\beta$-catenin signaling pathway.

\section{Discussion}

Oridonin is a diterpenoid compound isolated from the Chinese traditional medicine herb Rabdosia rubescens (25), which has attracted attraction due to its antitumor activities (26). Oridonin has been demonstrated to exert antitumor effects by inhibiting cell growth, proliferation and inducing apoptosis in multiple types of human cancer (27). However, the role of oridonin in the regulation of biological function of $\mathrm{CN}$ cells and the underlying molecular mechanisms remain unclear. The molecular regulatory mechanisms in $\mathrm{CN}$ cells are predominantly unexplored. In the present study, the data suggested that oridonin may suppress cell proliferation and induce apoptosis in $\mathrm{CN}$ cells, and that the function may be mediated by altering the Wnt/ $\beta$-catenin signaling pathway. To investigate the molecular mechanisms underlying the inhibition of cell proliferation and induction of apoptosis in $\mathrm{CN}$ cells, the expression levels of apoptosis-associated proteins, Bcl-2, Bax, cleaved caspase-3 and cleaved PARP, were detected by western blotting in the present study.

Anti-apoptotic Bcl-2 and pro-apoptotic Bax as well as Bcl-2 family proteins regulate mitochondrial permeability to alter apoptosis via an intrinsic pathway (28). In the present study, treatment with oridonin was able to decrease Bcl-2 expression and increase Bax expression in $\mathrm{CN}$ cells. Furthermore, the $\mathrm{Bax} / \mathrm{Bcl}-2$ ratio (an important parameter to measure the occurrence and levels of apoptosis) was significantly elevated.

Cleaved caspase-3, also known as mature or activated caspase-3, is a critical mediator of cell apoptosis (29). Pro-caspases require cleavage after aspartic acid residues, which result in one large and one small subunit. These subunits associate into an a2b2 tetramer to form the active enzyme $(30,31)$. Caspase-3 is able to cleave PARP to a specific $85-\mathrm{kDa}$ form, which is observed during apoptosis $(30,31)$. In the present study, treatment with oridonin was able to increase the levels of cleaved caspase- 3 and cleaved PARP, which was consistent with the promotion of apoptosis. These data indicated that oridonin-induced apoptosis in $\mathrm{CN}$ cells is associated with a decrease in Bcl-2 expression and an increase in Bax expression and activation of caspase-3.

The canonical Wnt signaling pathway serves an important role in the regulation of cell proliferation and apoptosis. It has been indicated that downstream target genes of the Wnt/ $\beta$-catenin pathway, including $c$-Myc and $\operatorname{cyclin} D 1$, 
are associated with apoptosis $(32,33)$. The Wnt signaling pathway is activated by interactions between the Wnt ligand and the Frizzled family receptor and the low-density lipoprotein receptor-related protein 5/6. The interaction leads to an accumulation of $\beta$-catenin in the cytoplasm and translocation into the nucleus due to the inactivation of the $\beta$-catenin destruction complex, Axin/adenomatous polyposis coli/glycogen synthase kinase-3 $\beta$ (34-37). Subsequently, $\beta$-catenin interacts with TCF4/LEF to activate the transcription of the target genes $B c l-2$, cyclin Dl and $c-M y c$, which control the transition from $\mathrm{G} 1$ to $\mathrm{S}$, resulting in abnormal cellular proliferation and apoptosis (38-40). The deregulation of Wnt signaling has been identified to be involved in tumorigenesis and the development of various types of cancer (41). It has been demonstrated that the Wnt pathway receptor, Frizzled-1, and the effector, T cell transcription factor 4 (TCF4), are highly expressed in $\mathrm{CN}$ cells and involved in the origin and expansion of neurocytoma from native subependymal progenitor cells (15), suggesting that $\mathrm{Wnt} / \beta$-catenin signaling is activated in $\mathrm{CN}$ cells. Combined with the reported finding that oridonin inhibits Wnt signaling in osteosarcoma cells (16), it is possible that oridonin may affect Wnt signaling in CN cells.

The stability of $\beta$-catenin is commonly used to evaluate the activity of the $\mathrm{Wnt} / \beta$-catenin signaling pathway. In the present study, it was revealed that oridonin was able to downregulate the level of $\beta$-catenin protein in $\mathrm{CN}$ cells in a concentration- and time-dependent manner. It has been previously reported that $\beta$-catenin is able to bind TCFs to stimulate cellular growth and proliferation in tumorigenesis by triggering the cell cycle regulator cyclin D1 (42). c-Myc, as the target of $\beta$-catenin protein, also serves a critical role in tumor prognosis (43). In the present study, it was demonstrated that cyclin D1 and c-Myc, the downstream targets of $\beta$-catenin, were reduced in $\mathrm{CN}$ cells, indicating that the $\mathrm{Wnt} / \beta$-catenin pathway was inhibited. Additionally, silencing $\beta$-catenin was able to augment oridonin-mediated inhibition of proliferation, whereas the overexpression of $\beta$-catenin was able to attenuate these effects in $\mathrm{CN}$ cells. These findings indicated that the antitumor activity of oridonin is mediated via the Wnt/ $\beta$-catenin signaling pathway in $\mathrm{CN}$ cells.

The potential molecular mechanism underlying the antitumor activities of oridonin has been investigated. Several studies indicated that certain signaling pathways and key genes associated with cell apoptosis and cells cycle were regulated by oridonin (44). For instance, oridonin is able to induce autophagy and apoptosis by upregulating p21 in prostate cancer cells (43) or can downregulate the phosphoinositide 3-kinase/Akt signaling pathway to suppress proliferation and induce caspase-dependent apoptosis in cervical cancer HeLa cells (45). In addition, oridonin may downregulate the activities of ERK and Akt and stimulate c-Jun and MAPK pathways to suppress proliferation and induce apoptosis in osteosarcoma cells (46). Oridonin has also been suggested to suppress the protein tyrosine kinase-Ras-Raf-JNK survival pathway and activate the ERK-p53 apoptotic pathway, resulting in cell cycle arrest and apoptosis in murine fibrosarcoma cells (47). Therefore, whether other signaling pathways or proteins take part in the regulation of antitumor activities of oridonin in $\mathrm{CN}$ cells remains to be elucidated.
In conclusion, the results of the present study indicated that oridonin exerts its antitumor function in $\mathrm{CN}$ cells by downregulating the activity of the $\mathrm{Wnt} / \beta$-catenin signaling pathway, suggesting that oridonin and other compounds from Chinese herbal medicines targeting the $\mathrm{Wnt} / \beta$-catenin signaling may be alternative drugs for $\mathrm{CN}$ therapy.

\section{Acknowledgements}

Not applicable.

\section{Funding}

The present study was supported by the National Key Research and Development Program of China (grant no. 2016YFE0126000), China National Natural Science Foundation (grant no.81570392), China Postdoctoral Science Foundation funded project (grant no.2016M591937), Natural Science Fund for Colleges and Universities in Jiangsu Province (grant no.16KJB320017), and High Level Talent Support Program of Yangzhou University (grant no. 137080077).

\section{Availability of data and materials}

The data sets used and/or analyzed during the current study are available from the corresponding author on reasonable request.

\section{Authors' contributions}

JL and YW were major contributors in the conception and design of the research and revision of the manuscript. Acquisition of data was performed by WW, SG and LW were the major contributors in the analysis and interpretation of data and statistical analysis. Drafting the manuscript was performed by JL.

\section{Ethics approval and consent to participate}

Ethics Committee of Jiamusi University approved this study.

\section{Patient consent for publication}

Written informed consent was obtained from patient for publication of this research article and any accompanying images.

\section{Competing interests}

The authors declare that they have no competing interests.

\section{References}

1. Kim DG, Paek SH, Kim IH, Chi JG, Jung HW, Han DH, Choi KS and Cho BK: Central neurocytoma: The role of radiation therapy and long term outcome. Cancer 79: 1995-2002, 1997.

2. Schild SE, Scheithauer BW, Haddock MG, Schiff D, Burger PC, Wong WW and Lyons MK: Central neurocytomas. Cancer 79: 790-795, 1997.

3. Schmidt MH, Gottfried ON, von Koch CS, Chang SM and McDermott MW: Central neurocytoma: A review. J Neurooncol 66: 377-384, 2004.

4. Kuo LM, Kuo CY, Lin CY, Hung MF, Shen JJ and Hwang TL: Intracellular glutathione depletion by oridonin leads to apoptosis in hepatic stellate cells. Molecules 19: 3327-3344, 2014. 
5. Kadota S, Basnet P, Ishii E, Tamura T and Namba T: Antibacterial activity of trichorabdal A from Rabdosia trichocarpa against Helicobacter pylori. Zentralblatt fur Bakteriologie: Int J Med Microbiol 286: 63-67, 1997.

6. Yang J, Jiang H, Wang C, Yang B, Zhao L, Hu D, Qiu G, Dong X and Xiao B: Oridonin triggers apoptosis in colorectal carcinoma cells and suppression of microRNA-32 expression augments oridonin-mediated apoptotic effects. Biomed Pharmacother 72 : $125-134,2015$.

7. Wang H, Wang YF, Liu TG, Xiang XL and Huang SL: Experimental study on anti-pancreatic cancer effect of oridonin Zhong Yao Cai 37: 1230-1233, 2014 (In Chinese).

8. Li Y, Wang Y, Wang S, Gao Y, Zhang X and Lu C: Oridonin phosphate-induced autophagy effectively enhances cell apoptosis of human breast cancer cells. Med Oncol 32: 365, 2015.

9. Wang YY, Lv YF, Lu L and Cai L: Oridonin inhibits mTOR signaling and the growth of lung cancer tumors. Anticancer Drugs 25: 1192-1200, 2014.

10. Bohanon FJ, Wang X, Ding C, Ding Y, Radhakrishnan GL, Rastellini C, Zhou J and Radhakrishnan RS: Oridonin inhibits hepatic stellate cell proliferation and fibrogenesis. J Surg Res 190: 55-63, 2014.

11. Bu HQ, Liu DL, Wei WT, Chen L, Huang H, Li Y and Cui JH: Oridonin induces apoptosis in SW1990 pancreatic cancer cells via p53- and caspase-dependent induction of p38 MAPK. Oncol Rep 31: 975-982, 2014.

12. Zhang CL, Wu LJ, Tashiro S, Onodera $\mathrm{S}$ and Ikejima $\mathrm{T}$ : Oridonin induces a caspase-independent but mitochondria- and MAPKdependent cell death in the murine fibrosarcoma cell line L929. Biol Pharm Bull 27: 1527-1531, 2004.

13. Behrens $\mathrm{J}$ and Lustig B: The Wnt connection to tumorigenesis. Int J Dev Biol 48: 477-487, 2004.

14. Knoepfler PS, Cheng PF and Eisenman RN: N-myc is essential during neurogenesis for the rapid expansion of progenitor cel populations and the inhibition of neuronal differentiation. Genes Dev 16: 2699-2712, 2002

15. Sim FJ, Keyoung HM, Goldman JE, Kim DK, Jung HW, Roy NS and Goldman SA: Neurocytoma is a tumor of adult neuronal progenitor cells. J Neurosci 26: 12544-12555, 2006.

16. Liu Y, Liu YZ, Zhang RX, Wang X, Meng ZJ, Huang J, Wu K, Luo JY, Zuo GW, Chen L, et al: Oridonin inhibits the proliferation of human osteosarcoma cells by suppressing Wnt/ $\beta$-catenin signaling. Int J Oncol 45: 795-803, 2014.

17. Roy NS, Benraiss A, Wang S, Fraser RA, Goodman R, Couldwell WT, Nedergaard M, Kawaguchi A, Okano H and Goldman SA: Promoter-targeted selection and isolation of neural progenitor cells from the adult human ventricular zone. J Neurosci Res 59: 321-331, 2000.

18. Roy NS, Wang S, Jiang L, Kang J, Benraiss A, Harrison-Restelli C, Fraser RA, Couldwell WT, Kawaguchi A, Okano H, et al: In vitro neurogenesis by progenitor cells isolated from the adult human hippocampus. Nat Med 6: 271-277, 2000.

19. Lee SJ, Kim JE, Paek SH, Keyoung HM, Kim DG and Jung HW: Primary cell culture of central neurocytomas. J Korean Neurosurg Soc 34: 238-244, 2003

20. Wu K, Yang Q, Mu Y,Zhou L, Liu Y,Zhou Q and He B: Berberine inhibits the proliferation of colon cancer cells by inactivating Wnt/beta-catenin signaling. Int J Oncol 41: 292-298, 2012.

21. He TC, Zhou S, da Costa LT, Yu J, Kinzler KW and Vogelstein B: A simplified system for generating recombinant adenoviruses. Proc Natl Acad Sci USA 95: 2509-2514, 1998.

22. Tang N, Song WX, Luo J, Luo X, Chen J, Sharff KA, Bi Y, He BC, Huang JY, Zhu GH, et al: BMP-9-induced osteogenic differentiation of mesenchymal progenitors requires functional canonical Wnt/beta-catenin signalling. J Cell Mol Med 13: 2448-2464, 2009

23. Livak KJ and Schmittgen TD: Analysis of relative gene expression data using real-time quantitative PCR and the 2(-delta delta C(t)) method. Methods 25: 402-408, 2001.
24. Feng M,Li J, Wang J, Ma C, Jiao Y, Wang Y, Zhang J, Sun Q, Ju Y, Gao L1 and Zhao Y: High glucose increases LPS-induced DC apoptosis through modulation of ERK1/2, AKT and Bax/Bcl-2. BMC Gastroenterol 14: 98, 2014

25. Abelson PH: Medicine from plants. Science 247: 513, 1990

26. Liu H, Qian C and Shen Z: Anti-tumor activity of oridonin on SNU-5 subcutaneous xenograft model via regulation of c-Met pathway. Tumour Biol 35: 9139-9146, 2014

27. Liu YQ, Mu ZQ, You S, Tashiro S, Onodera S and Ikejima T: Fas/FasL signaling allows extracelluar-signal regulated kinase to regulate cytochrome $\mathrm{c}$ release in oridonin-induced apoptotic U937 cells. Biol Pharm Bull 29: 1873-1879, 2006.

28. Jin S, Shen JN, Wang J, Huang G and Zhou JG: Oridonin induced apoptosis through Akt and MAPKs signaling pathways in human osteosarcoma cells. Cancer Biol Ther 6: 261-268, 2007.

29. Cheng Y, Qiu F, Ye YC, Tashiro S, Onodera S and Ikejima T: Oridonin induces $\mathrm{G} 2 / \mathrm{M}$ arrest and apoptosis via activating ERK-p53 apoptotic pathway and inhibiting PTK-Ras-Raf-JNK survival pathway in murine fibrosarcoma L929 cells. Arch Biochem Biophys 490: 70-75, 2009.

30. Stennicke HR and Salvesen GS: Caspases-controlling intracellular signals by protease zymogen activation. Biochim Biophys Acta 1477: 299-306, 2000.

31. Gray DC, Mahrus S and Wells JA: Activation of specific apoptotic caspases with an engineered small molecule-activated protease. Cell 142: 637-646, 2010.

32. Clevers H: Wnt/beta-catenin signaling in development and disease. Cell 127: 469-480, 2006.

33. Wharton KA Jr: Runnin' with the Dvl: Proteins that associate with Dsh/Dvl and their significance to Wnt signal transduction. Dev Biol 253: 1-17, 2003.

34. Rao TP and Kühl M: An updated overview on Wnt signaling pathways: A prelude for more. Circ Res 106: 1798-1806, 2010.

35. Minde DP, Anvarian Z, Rüdiger SG and Maurice MM: Messing up disorder: How do missense mutations in the tumor suppressor protein APC lead to cancer? Mol Cancer 10: 101, 2011.

36. Minde DP, Radli M, Forneris F, Maurice MM and Rüdiger Stefan GD: large extent of disorder in adenomatous polyposis coli offers a strategy to guard Wnt signalling against point mutations. PLoS One 8: e77257, 2013.

37. MacDonald BT, Tamai K and He X: Wnt/beta-catenin signaling: Components, mechanisms, and diseases. Dev Cell 17: 9-26, 2009.

38. Lopez J and Tait SW: Mitochondrial apoptosis: Killing cancer using the enemy within. Br J Cancer 112: 957-962, 2015.

39. Cohen GM: Caspases: The executioners of apoptosis. Biochem J 326: 1-16, 1997

40. Tetsu $\mathrm{O}$ and McCormick F: Beta-catenin regulates expression of cyclin D1 in colon carcinoma cells. Nature 398: 422-426, 1999.

41. Reya $\mathrm{T}$ and Clevers $\mathrm{H}$ : Wnt signalling in stem cells and cancer. Nature 434: 843-850, 2005

42. Damalas A, Ben-Ze'ev A, Simcha I, Shtutman M, Leal JF, Zhurinsky J, Geiger B and Oren M: Excess beta-catenin promotes accumulation of transcriptionally active p53. EMBO J 18: 3054-3063, 1999.

43. He TC, Sparks AB, Rago C, Hermeking H, Zawel L, da Costa LT, Morin PJ, Vogelstein B and Kinzler KW: Identification of c-MYC as a target of the APC pathway. Science 281: 1509-1512, 1998.

44. Klaus A and Birchmeier W: Wnt signalling and its impact on development and cancer. Nat Rev Cancer 8: 387-398, 2008.

45. Li CY, Wang EQ, Cheng Y and Bao JK: Oridonin: An active diterpenoid targeting cell cycle arrest, apoptotic and autophagic pathways for cancer therapeutics. Int J Biochem Cell Biol 43: 701-704, 2011.

46. Li X, Li X, Wang J, Ye Z and Li JC: Oridonin up-regulates expression of $\mathrm{P} 21$ and induces autophagy and apoptosis in human prostate cancer cells. Int J Biol Sci 8: 901-912, 2012.

47. Hu HZ, Yang YB and Xu XD: Oridonin induces apoptosis via PI3K/Akt pathway in cervical carcinoma HeLa cell line. Acta Pharmacol Sin 28: 1819-1826, 2007. 